\title{
A Prospective Randomized Control Trial Comparing Proximal Femoral Nail and Sliding Hip Screw in The Management of Trochanteric Fracture of The Femur
}

\author{
NK Karn, Ashish Jain, P Nepal, Mahi Pal Singh, N Das \\ B.P. Koirala Institute of Health Sciences, Dharan, Nepal
}

\begin{abstract}
Introduction: There are various implants designed for fixation of trochanteric fracture which can be extramedullary (Sliding hip screw) and intramedullary (Proximal Femoral Nail). A randomized controlled trial comparing these techniques was conducted at BP Koirala Institute of Health Sciences. Objective: To compare efficacy of proximal femoral nail and sliding hip screw in the management of trochanteric fractures. Methods: Patients in both groups were matched for age (mean 67 years, 50 to 100) and gender. We excluded all pathological fractures, patients presenting at more than one week, multiple fractures or any bone and joint disease interfering with rehabilitation. Results: The amount of blood loss and length of incision were significantly higher in the sliding hip screw group $(\mathrm{p}<0.05)$. The time of union, range of movement and Western Ontario and McMasterUniversity knee scores were comparable at two years. The mean Harris hip score was better in proximal femoral group. Conclusion: The number of patients showing shortening, external malrotation and varus angulation was more in sliding hip screw group. There was one case of wound infection and a single case of breakage of implant in sliding hip screw group.
\end{abstract}

Keywords: fracture trochanter, proximal femoral nail, sliding hip screw

\section{Introduction}

Fracture of the hip is a leading cause of death and disability in the elderly. ${ }^{1}$ Treatment goals for these patients include early rehabilitation, restoration of anatomical alignment and maintenance of the fracture reduction by internal fixation. ${ }^{2}$ There are various implants designed for fixation of trochanteric fracture which can be extramedullary (Sliding hip screw) and intramedullary (Proximal Femoral Nail). Theoretically, there is an improved biomechanical environment with an intramedullary device with a shorter lever arm, which provides more load sharing, indirect healing and allows less collapse to a stable

Address for correspondence:

Dr Navin Kumar Karn

Assistant Professor

Department of Orthopaedics, BPKIHS

Email:navinkarn@yahoo.com medial configuration and thus enables early rehabilitation and weight-bearing of the fractured extremity. The insertion by a limited exposure also may offer benefit because there is less soft tissue trauma, and this could lead to a reduced incidence of infection. A smaller wound also might minimize blood loss because fewer vessels are damaged ${ }^{3,4,5}$. A number of studies have reported the use of proximal femoral nail in the management of trochanteric fracture of the femur, but only few were comparative trials providing evidence of less operative trauma and speedier recovery especially in unstable fracture. ${ }^{6,7,8,9,10}$. If proximal femoral nail is to be widely accepted as an effective alternative to the sliding hip screw in the management of trochanteric fractures, a randomised controlled trial is required to compare effiacy with cost. This was the aim of our study. 


\section{Subjects and methods}

In 2007, 67 consecutive patients with a mean age of 67 years (50 to 100) presented with a trochanteric fracture. We excluded patients presenting more than a week after injury, those with pathological fractures, multiple fractures, or bone and joint disease that could interfere with rehabilitation. This left 60 patients available for the study. The patients were randomly selected for treatment either proximal femoral nail or by sliding hip screw. There were 30 in each group. All patients gave informed consent to be included in the study. The American Society of Anesthesiologists (ASA) scale was used to classify any co-morbidities. In the proximal femoral group 26 patients were classified as ASA grade 2, three as ASA grade 3 and one as ASA grade 4, while in the sliding hip screw group, 24 patients were classified as ASA grade 2 and six as ASA grade 3. Both the groups received regional anaesthesia in the form of epidural or spinal injection. Prior to fixation, the fractures were reduced under fluoroscopy, using a fracture table. Both groups received intravenous antibiotics before surgery, and orally thereafter, until one week after discharge from the hospital. In the proximal femoral group the fracture was reduced by longitudinal traction and the limb was placed in neutral or slight adduction to facilitate nail insertion through the greater trochanter. A straight lateral incision was made from tip of the greater trochanter, extending 4-6 $\mathrm{cm}$ proximally; the gluteus medius muscle was dissected in line with its fibers. The entry portal for the PFN was made at the tip of the greater trochanter, halfway between its anterior and posterior extent. A guide wire was inserted at the tip of the greater trochanter under image and was advanced into the femoral shaft in such a way that it is located in the middle of the shaft in both views. We reamed the proximal part of the femur with a trochanteric flexible $14 \mathrm{~mm}$ reamer. After mounting the appropriate sized nail on the insertion device the nail was introduced manually into the femoral shaft. Via the aiming arm, which was attached to the insertion device, first the guide wire for the neck screw was introduced into the femoral neck in such a way that the screw was placed in lower half of the neck on the antero-posterior view and centrally on the lateral view. The guide pin for the anti rotational hip pin was introduced. The hip pin was introduced first with the tip just about $25 \mathrm{~mm}$ medial to the fracture line, and then the neck screw of appropriate size was inserted. The distal screw was placed with the help of same zig. The stability of the construct was assessed and wounds were closed in layers. Antiseptic dressing was done.

In the sliding hip screw group, a routine lateral approach to the proximal femur was used, and the sliding screw was introduced using a standard technique. ${ }^{11}$ The intra-operative time was measured from incision to closure. The blood loss was measured as the difference in weight between the dry swabs and those soaked in blood. After surgery all patients had a gradually progressive programme of weightbearing using a walking frame, from the first day of surgery. Appropriate physiotherapy was advised for hip and knee movement. The patients were followed two weeks for removal of sutures.. All the patients were reviewed at $6,12,18$ and 24 weeks. Observations regarding shortening, malunion in external rotation, varus angulation, pain at the hip and knee, range of movement of the hip and knee, evidence of union and infection were recorded. The final follow-up was at 24 months, when function of the hip was assessed using a modified Harris hip score $^{12}$ and the function of the knee assessed using a modified Western Ontario and McMasterUniversity Osteoarthritis (WOMAC) index. ${ }^{13}$

This study had ethical approval. Statistical analysis. The data were entered using Microsoft EXCEL version 8 (Microsoft Corporation, Redmond, Washington).The success of the randomisation was tested by comparing descriptive variables such as age, gender, mechanism of injury, type of injury and category of fracture. Any discrepancies were measured as the difference between the means in both groups. The significance of these differences was measured using parametric analysis of variance student-t-test or the non-parametric Menn whitney test derived from the Epi Info computer program (Environmental System Research Inc., New Delhi,India).

\section{Results}

Both groups were comparable in terms of age, gender, mechanism of injury and category of fracture $(\mathrm{p}>0.05)($ Table 1). 
Table 1: Patients detail

\begin{tabular}{|lcccc|}
\hline & PFN & SHS & Odds ratio & p-value \\
\hline Age in yrs(mean;range) & $66.56(53-100)$ & $67.80(50-87)$ & & 0.6385 \\
Gender M:F & $18: 12$ & $12: 18$ & 2.25 & 0.121 \\
Mechanism of injuryFallRoad traffic accident & 219 & 228 & & 0.774 \\
Type of injury Direct Indirect & 282 & 282 & 1.036 & 0.6292 \\
Category of fracture Stable Unstable & 1614 & 1911 & 0.662 & 0.432 \\
ASA grading* & & & & \\
2 & 26 & 24 & \\
3 & 3 & 6 & \\
4 & 1 & 0 & & \\
\hline
\end{tabular}

*ASA, American Society of Anaesthesiologist

The postoperative radiographs of proximal femoral nail and sliding hip screw are shown in Fig1.
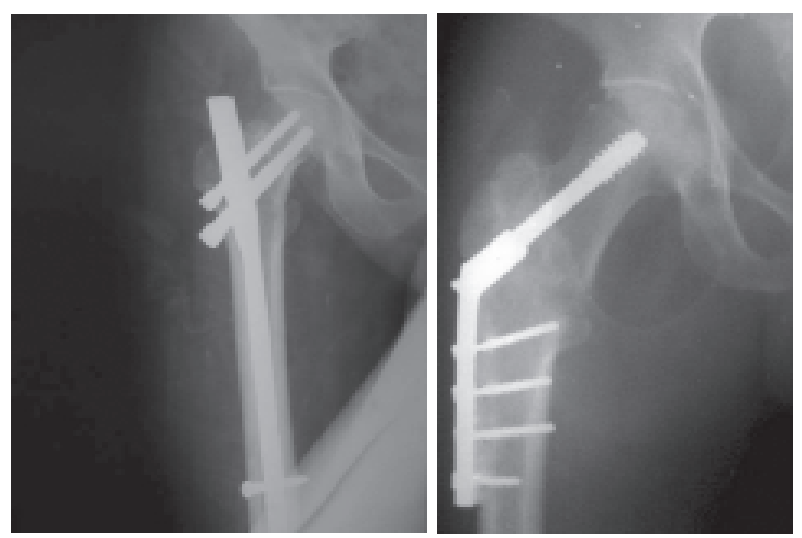

Figl Fixation with proximal femoral nail and
All fractures united clinically and radiologically at 12 weeks. Duration of surgery was comparable in both the groups proximal femoral nail 93 minutes (80 to100) compared with the sliding hip screw group (mean91.50 minutes, 60 to 110 ). The proximal femoral group lost less blood, a mean of $409.33 \mathrm{ml}$ (400 to 420), compared with a mean of $499.33 \mathrm{ml}$ (480 to 520) in sliding hip screw group.

At final follow-up, the number of patients with shortening external malrotation and varus angulation was more in sliding hip screw.(Table2).

Table 2: Showing comparison of the outcomes in the two groups

\begin{tabular}{|lccc|}
\hline Follow up (wks) & $\begin{array}{c}\text { Proximal femoral } \\
\text { nail (mean SD) }\end{array}$ & $\begin{array}{c}\text { Sliding hip } \\
\text { screw (mean SD) }\end{array}$ & p-value \\
\hline Shortening & & & \\
6 & $0.08(0.23)$ & $0.28(0.48)$ & 0.046 \\
12 & $0.08(0.19)$ & $0.26(0.42)$ & 0.033 \\
18 & $0.05(0.15)$ & $0.21(0.37)$ & 0.030 \\
24 & $0.01(0.09)$ & $0.17(0.27)$ & 0.006 \\
Malunion in external rotation in 24 wks(degree) & & & \\
0 & 30 & 27 & \\
5 & 0 & 3 & \\
Range of movement of the hip(degree) & & $209(20.88)$ & 0.374 \\
6 & $204(20.87)$ & $232(16.74)$ & 0.070 \\
12 & $224(16.12)$ & $247(15.96)$ & 0.096 \\
18 & $240(16.0)$ & $271(22.04)$ & 0.001 \\
24 & $289(16.04)$ & & \\
Range of movement of the knee(degree) & & $118(12.22)$ & 0.334 \\
6 & $120(18.12)$ & $126(6.74)$ & 0.634 \\
12 & $128(14.12)$ & $128(6.62)$ & 0.628 \\
18 & $130(7.18)$ & $128(6.62)$ & 0.628 \\
24 & $130(7.18)$ & 22 & 0.0034 \\
Varus angulation at 24wks & 30 & 8 & \\
5 & 0 & & \\
\hline
\end{tabular}


The pain in hip and knee was comparable. The range of movement of the hip was comparable in both the groups. A single patient in the sliding hip screw group had wound dehiscence which required re-admission, debridement and secondary wound closure. It had healed by seven days. The mean modified Harris hip score in proximal femoral nail was 94 which was significantly greater than and sliding hip screw $90(\mathrm{p}<0.019)$. The WOMAC index was 3 , in both groups. The mean cost of the treatment in proximal femoral group (US \$280, \$270 to \$286) was significantly greater than in the sliding hip screw fixation group (US\$239, \$236 to \$240) (p $<0.0001)$. There was a single case of implant failure in sliding hip screw group. (Fig 2)

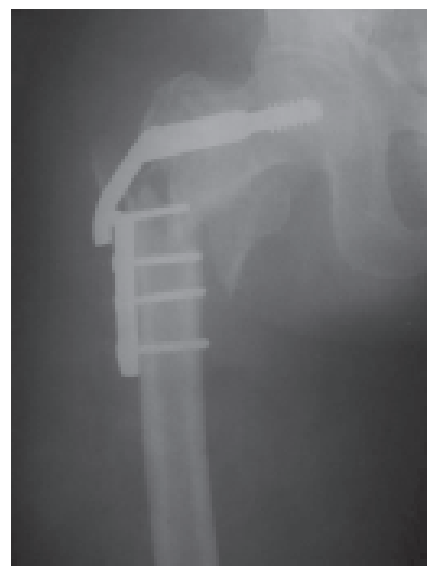

Fig 2 Implant failure in sliding hip screw group

\section{Discussion}

Sliding hip screws treat osteoporotic pertrochanteric fractures, inspite of substantial rates of fixation failure, poor fuctional outcome and associated morbidity. ${ }^{14}$

Intramedullary implants have revolutionized the management of fracture trochanter, as they carry all possible advantage over their counterparts, extramedullary implants. They are inserted with minimal soft tissue injury technique, lesser blood loss, lesser limb shortening, lesser decrease in medial offset, so, less abductor lurch while walking, and faster rehabilitation. . It provides stable internal fixation with biomechanical advantage of a shorter lever arm, which is more stable under loading. The anti-rotation screw prevents the rotational element of the proximal fracture fragment; fluting the nail tip decreases the stress at the distal end. ${ }^{15}$

Dominigo et al. ${ }^{6}$, Porecha et al. ${ }^{15}$ and Hardy et al. ${ }^{16}$ has demonstrated the proximal femoral nail was associated with a significantly less blood loss as compared to sliding hip screw intraoperatively. Our study support this finding.

Pajarinen et al. ${ }^{10}$ reported a faster ability to bear weight in patients of intertrochanteric fractures treated with proximal femoral nail rather than sliding hip screw. We found ability to bear weight in both the groups were comparable.

We found size of the incision was smaller in proximal femoral nail as compared to sliding hip screw. These findings were supported by Klinger et al. ${ }^{7}$., Morihara et $\mathrm{al}^{8}$ and Porecha et al. ${ }^{15}$

There are varying outcome in term of duration of surgery. Hardy et al. ${ }^{16}$ found duration of surgery was higher in intramedullary nail. Klinger et $\mathrm{al}^{7}$ found duration of surgery was less in proximal femoral nail as compared to sliding hip screw. Our study did not detect any difference in respect to duration of surgery which was comparable to the study done by Morihara et al. ${ }^{8}$ and Saudan et al. ${ }^{17}$. This varying outcome in different studies are attributable to the expertise of the surgeon as well as implant design by various companies.

We found the duration of hospital stay was comparable in both groups.

Shortening external malrotation and varus angulation was found more with sliding hip screw group. This could be correlated to the study of Hardy et al ${ }^{16}$ who documented shortening significantly less in proximal femoral nails $(\mathrm{p}=0.019)$ and even more so in unstable fractures $(\mathrm{p}<0.001)$. .

Modified Harris hip score was found to be significantly higher in patients treated with proximal femoral nail than SHS which proves that proximal femoral nail renders better functional ability to patients of intertrochanteric fracture in the long term than sliding hip screw. These findings are supported by the works of Dominigo et $\mathrm{al}^{5}$, Klinger et $\mathrm{al}^{7}$, Nuber et $\mathrm{al}^{9}$ Pajarinen et $\mathrm{al}^{10}$ and Porecha et $\mathrm{al}^{15}$

However cost was seen to be a major drawback with proximal femoral nail as sliding hip screw is significantly cheaper than proximal femoral nail. This may have a major bearing in a developing country setting.

\section{Conclusion}

This study has shown that proximal femoral nail though costly is superior to sliding hip screw in terms of blood loss, incision length, function of the hip and less complications but equal union rate. 


\section{References}

1. Christodoulou N, Sdrenias CV External fixation of select intertrochanteric fractures with single hip screw. Clin Orthop 2000; 381:204-211.

2. Singh AK, Thong G, Laloo N, Singh AM, Singh SN Management of trochanteric fractures. Indian J Orthop 2006; 40:100-102

3. Boriani S, Bettelli G, Zmerly $\mathrm{H}$ et al. Results of the multicentric Italian experience on the Gamma nail: A report on 648 cases. Orthopaedics 1991; 14:1307-1314.

4. Halder SC The Gamma nail for peritrochanteric fractures. . J Bone Joint Surg Br 1992; 74-B:340344

5. Leung KS, So WS, Shen WY, et al Gamma nails and dynamic hip screws for peritrochanteric fractures: a randomized prospective study in elderly patients. J Bone Joint Surg 1992 ; 74B:345-351

6. Dominigo J,Herrera A, Martinez A Results of osteosynthesis with the ITST nail in fractures of the trochanteric region of the femur. International Orthopaedics (SICOT) 2008; 32:767-782

7. Klinger HM,Baums MH ,Eckert M , Naugebauer R A comparative study of unstable per- and intertrochanteric femoral fractures treated with dynamic hip screw (DHS) and trochanteric butt-press plate vs. proximal femoral nail (PFN)].Zentralbl Chir (German) 2005 ; 130(4):301-6

8. Morihara T, Arai Y, Tokugawa S, Fujita S, Chatani K, Kubo T. Proximal femoral nail for treatment of trochanteric fractures. J Orthop Surg (Hong Kong). 2007; 15(3):273-277

9. Nuber S,Schonweiss T,Ruter A. Stabilisation of unstable trochanteric femoral fractures. Dynamic hip screw (DHS) with trochanteric stabilisation plate vs. proximal femur nail (PFN). Unfallchirug (German) 2003 Jan;106(1):39-47
10. Pajarinen J, Lindahl J,Michelsson O, Savolainen V Hirvensalo E Pertrochanteric femoral fractures treated with a dynamic hip screw or a proximal femoral nail: A randomized study comparing post-operative rehabilitation .J Bone Joint Surg 2005 ; 87-B: $76-81$

11. LaVelle DG Fractures of hip. In: Canale ST, (ed ) Campbell's operative orthopaedics $10^{\text {th }}$ edn 2003, Vol. 3:2873-938.

12. Harkess JW Arthroplasty of hip. In: Canale ST( ed) Campbell's operative orthopaedics $10^{\text {th }}$ edn 2003, Vol. 1:315-482

13. Das SK, Sajwan N, Srivastava R, et al KGMC index: a modified WOMAC index to evaluate response in Indian patients with osteoarthritis knee. J Indian Rheumatology Association 1998;6:46-49.

14. Larsson $S$ Treatment of osteoporotic fractures Scand J Surg 2002; 91:140-6.

15. Porecha M M, Parmar D S, Chawada H R, Parmar R D Long proximal femoral nails versus sliding hip screw-plate device for the treatment of intertrochanteric hip fractures - A randomized prospective study in 100 elderly patients. The Internet Journal of Orthopedic Surgery. 2009;12:1 032-035 Volume 12 Number 1.

16. Hardy D C R, Descamps P, Krallis P, Fabeck L, Smets F, Bertens C I, Delince P Use of an Intramedullary Hip-Screw Compared with a Compression Hip-Screw with a Plate for Intertrochanteric Femoral Fractures. A Prospective, Randomized Study of One Hundred Patients.J. Bone Joint Surg. 1998; 80-A: 618-630

17. Saudan M, Lübbeke A, Sadowski C, Riand N, Stern R, Hoffmeyer P Pertrochanteric fractures : is there an advantage to an intramedullary nail ? : a randomized, prospective study of 206 patients comparing the dynamic hip screw and proximal femoral nail. J Orthop Trauma. 2002 ;16(6):38693 